\title{
System accuracy evaluation of the systems for selfmonitoring of blood glucose GL50 evo and GL 44 following DIN EN ISO 15197:2015 - A comparison of accuracy in hypo $(<70 \mathrm{mg} / \mathrm{dL})$ - and hyper glycemic $(\geq 180$ $\mathrm{mg} / \mathrm{dL}$ ) glucose ranges
}

\author{
Salzsieder $\mathrm{E}^{1^{*}}$, Puchert $\mathrm{A}^{1}$, Ernst-Joachim Freyse ${ }^{1}$ and Berg $\mathbf{S}^{1,2}$ \\ ${ }^{1}$ Institute of Diabetes, Gerhardt Katsch, Karlsburg, Germany \\ ${ }^{2}$ University Medicine Greifswald, Germany
}

\begin{abstract}
Abbreviations: CE: Conformite Europeene; ISO: International Organization for Standardization; SMBG: Self-Monitoring of Blood Glucose.
\end{abstract}

Ongoing standardized verification of the accuracy of blood glucose meters systems for self-monitoring post-launch is important clinically and helps confirm appropriate continues performance of selfmonitoring blood glucose (SMBG) systems [1]. In addition, publication of such studies is increasingly becoming a component of evidence-based purchase decision making. ISO 15197:2015, [2] for which mandatory compliance is recommended for SMBG systems by 2015, [3] has tighter accuracy requirements than ISO 15197:2003, [4] and outlines current minimum accuracy standards necessary in Europe for CE marking.

In the present study, a postmarketing evaluation of the CE-marked GL50 evo and GL44 systems were performed in accordance with ISO 15197:2015 protocols and requirements. The GL50 evo and GL44 systems were supplied in Germany from the Beurer $\mathrm{GmbH}$, Germany. A declaration of conformity from the manufacturer of the two measuring systems was available before the start of the study, so that only the GL50 evo was used in the tests, but the results documented the quality of bothsystems. Two GL50 evo systems (serial number: GL55 T1 and GL55 T2) and strips from 3 different lots (A 10/1, A 10/3,A 10/4) with expiry dates March 2017 respectively) were supplied by the manufacturer. The study was conducted from April 21 to May 05, 2015, at the Institute of Diabetes "Gerhardt Katsch," Karlsburg, Germany. Ethical approval for the study was obtained from the Ethics Committee of the University of Greifswald in July 2014.

Ear lobe capillary blood samples were taken from 118 subjects for duplicate glucose determination using the GL50 evo and the glucose oxidase based YSI2300 STAT PLUS (YSI Incorporated, Yellow Springs, Ohio, USA) plasma glucose reference method. Trueness and precision of the comparison assay were verified using a range of YSI bioanalytical standards and controls. The prescribed limits for the hematocrit values, to be between $20 \%$ and $60 \%$, were reached by the patient samples and after examination of glucose concentration ranges using the YSI, 52 subjects were evaluated in the study to consider the hypo- and hyperglycemic range.
To analyze the system accuracy of the monitoring system in hypo$(<70 \mathrm{mg} / \mathrm{dL})$ and hyper-glycemic ranges $(\geq 180 \mathrm{mg} / \mathrm{dl})$ the statistic was done especially for these ranges.

In the glucose range $<70 \mathrm{mg} / \mathrm{dL}$ in summary $100 \%$ of the values and in the range $\geq 180 \mathrm{mg} / \mathrm{dl}$ in summary $98.2 \%$ full filled the quality criteria of the ISO 15197. Important differences between the three tested lots were not shown; detailed data are presented in table 1 . The table 2 and 3 demonstrates performance for the named hypo- and hyperglycemic ranges, in relation to the minimum accuracy requirements of ISO 15197:2015 where for each of the 3 lots of strips at least $95 \%$ of results must fall within $\pm 15 \mathrm{mg} / \mathrm{dl}$ of the comparison measurement results at blood glucose concentrations $<100 \mathrm{mg} / \mathrm{dl}$ and within $\pm 15 \%$ at

Table 1. System accuracy of Beurer GL50 evo/ GL44 for glucose concentrations $<70 \mathrm{mg}$ / dL

\begin{tabular}{|c|c|c|c|}
\hline & \multicolumn{3}{|c|}{ ISO 15197:2015 criteria } \\
\hline Strip lot & within $\pm \mathbf{5 m g} / \mathbf{d L}$ & within $\pm \mathbf{1 0 m g} / \mathbf{d L}$ & within $\pm \mathbf{1 5 m g} / \mathbf{d L}$ \\
\hline A $10 / 1$ & $13 / 30(43.33 \%)$ & $29 / 30(96.67 \%)$ & $30 / 30(100 \%)$ \\
\hline A $10 / 3$ & $15 / 30(50.00 \%)$ & $30 / 30(100 \%)$ & $30 / 30(100 \%)$ \\
\hline A $10 / 4$ & $23 / 30(76.67 \%)$ & $30 / 30(100 \%)$ & $30 / 30(100 \%)$ \\
\hline $\begin{array}{c}\text { Three lots } \\
\text { in summary }\end{array}$ & $\mathbf{5 1 / 9 0}(\mathbf{5 6 . 6 7} \%)$ & $\mathbf{8 9} / 90(\mathbf{9 8 . 8 9} \%)$ & $\mathbf{9 0 / 9 0}(\mathbf{1 0 0} \%)$ \\
\hline
\end{tabular}

Table 2. System accuracy of Beurer GL50 evo/ GL44 for glucose concentrations $\geq 180$ $\mathrm{mg} / \mathrm{dL}$

\begin{tabular}{|c|c|c|c|}
\hline & \multicolumn{3}{|c|}{ ISO 15197:2015 criteria } \\
\hline Strip lot & within $\pm \mathbf{5} \%$ & within $\pm \mathbf{1 0} \%$ & within $\pm \mathbf{1 5} \%$ \\
\hline A $10 / 1$ & $29 / 74(39.19 \%)$ & $56 / 74(75.68 \%)$ & $73 / 74(98.65 \%)$ \\
\hline A $10 / 3$ & $29 / 74(39.19 \%)$ & $58 / 74(78.38 \%)$ & $72 / 74(97.30 \%)$ \\
\hline A $10 / 4$ & $30 / 74(40.54 \%)$ & $63 / 74(85.14 \%)$ & $73 / 74(98.65 \%)$ \\
\hline $\begin{array}{c}\text { Three lots } \\
\text { in summary }\end{array}$ & $88 / 222(39.64 \%)$ & $177 / 222(79.73 \%)$ & $218 / 222(98.20 \%)$ \\
\hline
\end{tabular}

${ }^{*}$ Correspondence to: Eckhard Salzsieder, Institute of Diabetes, Gerhardt Katsch, Karlsburg, Germany, E-mail: salzsied@diabetes-karlsburg.de

Received: September 02, 2019; Accepted: September 16, 2019; Published: September 18, 2019 
Salzsieder E (2019) System accuracy evaluation of the systems for selfmonitoring of blood glucose GL50 evo and GL 44 following DIN EN ISO 15197:2015 - A comparison of accuracy in hypo $(<70 \mathrm{mg} / \mathrm{dL})$ - and hyper glycemic $(\geq 180 \mathrm{mg} / \mathrm{dL})$ glucose ranges

Table 3. Numbers and percentages of results within system accuracy limits of ISO 15197:2015 at blood glucose levels $<70 \mathrm{mg} / \mathrm{dL}$ and $\geq 180 \mathrm{mg} / \mathrm{dL}$

\begin{tabular}{|c|c|c|c|c|}
\hline SMBG system & \multicolumn{4}{|c|}{ ISO 15197:2015 criteria within $\pm \mathbf{1 5}$ mg/dl and $\pm \mathbf{1 5} \%$} \\
\hline Meter & Strip lot & Individual lots & 3 lots combined & Within consensus error grid zones A and B \\
\hline GL50 evo/ & A 10/1 & $103 / 104(99.04 \%)$ & $308 / 312(98.72 \%)$ & \\
\hline GL44 & A 10/3 & $102 / 104(98.08 \%)$ & \\
\hline & A 10/4 & $103 / 104(99.04 \%)$ & \\
\hline
\end{tabular}

concentrations $\geq 100 \mathrm{mg} / \mathrm{dl}$. The standard also requires that at least $99 \%$ of individual results fall within consensus error grid zones A and B [5,6] when clinical accuracy is evaluated with 3 test strip lots.

\section{Conclusion}

In conclusion, this study demonstrates that the GL50 evo and GL44 SMBG meter systems in hypo- and hyper-glycemic ranges fulfils and exceeds the minimum analytical and clinical accuracy requirement of ISO 15197:2015. There are no differences in the accuracy between the glucose values $<70 \mathrm{mg} / \mathrm{dL}$ and $\geq 180 \mathrm{mg} / \mathrm{dL}$.

\section{Acknowledgments}

Beurer $\mathrm{GmbH}$ were permitted to review and comment on the manuscript, but final decision on content was retained by the authors.

\section{Declaration of conflicts of interest}

The author(s) declared the following potential conflicts of interest with respect to the research, authorship, and/or publication of this article: All authors are employees of the Institut of Diabetes, Karlsburg, Germany, which carries out studies evaluating blood glucose meter systems on behalf of various companies.

\section{Funding}

The author(s) disclosed receipt of the following financial support for the research, authorship, and/or publication of this article: This study was funded by Beurer GmbH Söflinger Str 218, 89077 Ulm Germany.

\section{References}

1. Klonoff DC, Prahalad P (2015) Performance of cleared blood glucose monitors. $J$ Diabetes Sci Technol 9: 895-910. [Crossref]

2. International Organization for Standardization. In vitro diagnostic test systemsrequirements for blood-glucose monitoring systems for self-testing in managing diabetes mellitus. ISO 15197: 2013.

3. Baumstark A, Schmid C, Pleus S, Rittmeyer D, Haug C, et al. (2014) Accuracy assessmen of an advanced blood glucose monitoring system for self-testing with three reagent system lots following ISO 15197:2013. J Diabetes Sci Technol 8: 1241-1242. [Crossref]

4. International Organization for Standardization. In vitro diagnostic test systemsrequirements for blood-glucose monitoring systems for self-testing in managing diabetes mellitus. EN ISO 15197: 2003.

5. Parkes JL, Slatin SL, Pardo S, Ginsberg BH (2000) A new consensus error grid to evaluate the clinical significance of inaccuracies in the measurement of blood glucose. Diabetes Care 23: 1143-1148. [Crossref]

6. Bland JM, Altman DG (1986) Statistical methods for assessing agreement between two methods of clinical measurement. Lancet 1: 307-310. [Crossref]

Copyright: $@ 2019$ Salzsieder E. This is an open-access article distributed under the terms of the Creative Commons Attribution License, which permits unrestricted use, distribution, and reproduction in any medium, provided the original author and source are credited. 